\title{
Electrocardiographic Changes in Leptospirosis
}

\author{
MALCOLM PARSONS,* M.A., M.R.C.P.
}

Brit. med. F., 1965, 2, 201-203

The finding of electrocardiographic (E.C.G.) abnormalities in patients with leptospirosis who show clinical evidence of cardiac involvement is well recognized. In a review of the subject Sodeman and Killough (1951) reported the unexpected discovery of abnormalities in three patients without such clinical signs, and expressed the opinion that "an active interest in the [cardiovascular] system is necessary to establish involvement." The fact that an apparently normal E.C.G. taken in the first week of the illness might give such evidence if compared with a later record supported their thesis. Moreover, Mackay-Dick and Robinson (1957) subsequently demonstrated transient minor changes in the QRST complex in two out of six consecutive patients with uncomplicated leptospirosis.

Apart from this small series, no systematic search for latent cardiac involvement in leptospirosis has been made. In an attempt to remedy this, the present paper deals only with patients in whom there was no clinical evidence of heart disease. A comparable group of patients with malaria was also studied to find whether the changes observed were specific or associated with the response to fever.

\section{Patients Investigated and Methods}

This paper concerns 25 soldiers suffering from leptospirosis, whose ages ranged from 17 to 34 years. Eleven were New Zealanders, six Gurkhas, four Australians, three English, and one American. In each case the clinical diagnosis was later confirmed by a diagnostic rise in the antibody titre in a haemolytic test for leptospirosis done on paired sera. The series includes all patients with this disease admitted to the British Military Hospital, Kamunting, Malaya, during an 18-month period in 1960-2 and who had at least two E.C.G.s done during the illness.

When first examined, none of these patients had clinical evidence of congestive cardiac failure, cardiac enlargement, pericarditis, valvular disease, hypertension, or hypotension. None had an arrhythmia, although most had a tachycardia. Chest $x$-ray films, taken routinely on admission, confirmed the normal heart size.

The first E.C.G. record was taken during the first week of the clinical illness in $84 \%$, and during the first three days in $40 \%$. The second record was taken about eight days later, when the patient was afebrile. In all but three cases the first E.C.G. was taken before penicillin treatment was started.

For comparison, a second series of E.C.G.s was done on 18 febrile soldiers shown by clinical evidence, microscopical demonstration of the parasite, and response to therapy to have malaria. The E.C.G. records were taken in the same way during the febrile stage, and about a week later.

\section{E.C.G. in Patients wth Leptospirosis}

$P, Q R S$, and $T$ Waves.-Significant abnormalities were found mainly in the $R, S$, and $T$ waves. The $P$ and $Q$ waves were normal and unchanged throughout. The $\mathrm{R}$ wave was less than

\footnotetext{
* Formerly Junior Specialist in Medicine and Officer-in-Charge, Medical Division, British Military Hospital, Kamunting, Malaya. Now at the Hammersmith Hospital, London.
}

$5 \mathrm{~mm}$. tall in the most favourable standard lead, and in V4 or $\mathrm{V} 7$ in a third of all first records. The QRS complex was less than $7 \mathrm{~mm}$. tall in the most favourable standard lead in these cases. Apart from the occasional failure of a small $R_{v 7}$ to increase in size, the $\mathrm{R}$ waves throughout all second records were within the accepted limits of the normal range. Nearly all patients showed an increase in the size of the $R$ waves in standard and chest leads as the fever abated. The greatest increase in size in the standard leads was usually in lead II, and the average of the greatest increases was $4.6 \mathrm{~mm}$. The greatest increase in the chest leads was in V4, and the average $6.5 \mathrm{~mm}$. (Table I). Forty-four per cent. of patients showed an increase of $3 \mathrm{~mm}$. or more in the height of the $\mathrm{R}$ wave in two standard leads, and $36 \%$ an increase of $3 \mathrm{~mm}$. or more in two chest leads. The $S$ wave decreased in size in a standard lead in two-thirds of the patients as the fever abated. The decrease averaged $1.7 \mathrm{~mm}$., and was usually seen in lead I or II. $S_{v_{4}}$ and $S_{v 7}$ also decreased in size, but $S_{v_{1}}$ usually showed an increase. The $T$ wave in leads I and II was less than $1.5 \mathrm{~mm}$. tall in $72 \%$ of all first records, and $\mathrm{T}_{\mathrm{v}_{4}}$ or $\mathrm{T}_{\mathrm{v} 7}$ was reduced in size in $52 \%, \mathrm{~T}_{\mathrm{v}_{4}}$ being inverted in $28 \%$. During recovery there was a general increase in the size of the $T$ wave in all standard and chest leads. The change was most marked in leads I, II, and V4 (Table II).

TABLE I.-Changes in $R$ Wave During Recovery from Malaria and Leptospirosis. Note the Comparable Increase in Height of $R$ Wave Leptospirosis. Note the Comparable
During Recovery from these Fevers

\begin{tabular}{|c|c|c|}
\hline & Leptospirosis & Malaria \\
\hline $\begin{array}{l}\text { Increase in height of } R \text { wave occurs in one stan- } \\
\text { dard lead... } . . . \quad . \\
\text { Cases in which maximum } R \text { increase occurs in } \\
\text { lead II } . . . \\
\text { Mean of maximum } \ddot{R} \text { increases in standard leads } \\
\text { Range of maximum } R \text { increases } \ldots \quad \ldots\end{array}$ & $\begin{array}{c}92 \% \\
56 \% \\
4.6 \mathrm{~mm} . \\
1-9 \mathrm{~mm} .\end{array}$ & $\begin{array}{c}89 \% \\
55 \% \\
5 \mathrm{~mm} . \\
1-16 \mathrm{~mm} .\end{array}$ \\
\hline 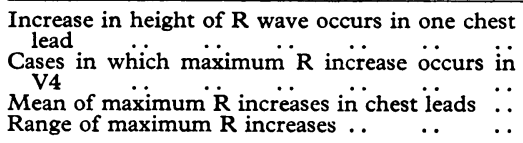 & $\begin{array}{c}76 \% \\
47 \% \\
6.5 \mathrm{~mm} . \\
1-17 \mathrm{~mm} .\end{array}$ & $\begin{array}{c}89 \% \\
67 \% \\
6.3 \mathrm{~mm} . \\
1-16 \mathrm{~mm} .\end{array}$ \\
\hline
\end{tabular}

TABLE II.-T-wave Changes During Recovery from Leptospirosis and Malaria. Note the Comparable Increase in Height of $T W$ ave During Recovery

\begin{tabular}{|c|c|c|}
\hline & Leptospirosis & Malaria \\
\hline $\begin{array}{l}\text { Cases in which } T \text { wave increases in height in a } \\
\text { standard lead .. } \\
\text { Cases in which greatest increase occurs in I or II } \\
\text { Mean of maximum T increases in standard leads } \\
\text { Range of maximum increases in height of } T \text { waves }\end{array}$ & $\begin{array}{l}96 \% \\
56 \% \\
2.7 \mathrm{~mm} \\
1-5 \mathrm{~mm}\end{array}$ & $\begin{array}{c}79 \% \\
56 \% \\
2 \cdot 1 \mathrm{~mm} \\
1-3 \mathrm{~mm}\end{array}$ \\
\hline $\begin{array}{l}\text { Cases in which } \mathrm{T} \text { wave increases in height in a } \mathrm{V} \\
\text { lead } \\
\text { Cases in which greatest increase occurs in } \mathrm{V}_{4} \quad . \\
\text { Mean of maximum T increases in chest leads } \ldots \\
\text { Range of maximum increases in height of } \mathrm{T} \text { waves }\end{array}$ & $\begin{array}{l}96 \% \\
68 \% \\
3.5 \mathrm{~mm} \text {. } \\
1-8 \mathrm{~mm}\end{array}$ & $\begin{array}{l}89 \% \\
78 \% \\
3.7 \mathrm{~mm} . \\
1-8 \mathrm{~mm} .\end{array}$ \\
\hline
\end{tabular}

Serial E.C.G.s showed that by the eleventh day of the clinical illness the record had returned to normal, and no further major changes occurred.

Other Abnormalities.-Elevation of the $\mathrm{S}-\mathrm{T}$ segment by about $1 \mathrm{~mm}$. occurs in $20 \%$ of second records, especially in leads I and V7 after the disappearance of an $S$ wave. The pulse rate increased at the rate of 6 beats/minute/degree Fahrenheit. Occasional ventricular extrasystoles were seen in two first records, and one patient developed atrial fibrillation late in his illness. The $P-R$ interval was normal throughout, with the 
exception of one reading of $0.22 \mathrm{sec}$. on a first record. There was no consistent change during recovery. The QRS complex rarely lasted longer than $0.1 \mathrm{sec}$. and never longer than $0.12 \mathrm{sec}$. It varied little with temperature. One set of records showed left and one right bundle-branch block throughout. The Q-Tc interval often exceeded $0.42 \mathrm{sec}$. in both sets of records. It did not show any consistent change during recovery.

\section{E.C.G. in Patients with Malaria}

Identical changes occurred in patients with malaria. The $\mathrm{R}$ waves were abnormally small in all leads in about $30 \%$ of first records, and increased in height in nearly $90 \%$ during recovery. The change was best seen in leads II and V4, and was of the order of $5 \mathrm{~mm}$. (Table I). Simultaneously I, II, V4, and V7 decreased in height.

The $\mathrm{T}$ wave was abnormally flat in standard leads in $72 \%$ of the first records, and $\mathrm{T}_{\mathrm{v}_{4}}$ was flat or inverted in $39 \%$. Nearly all returned to normal, and $80 \%$ of patients showed an increase in the height of the $\mathrm{T}$ wave of the order of 2 to $3 \mathrm{~mm}$. during recovery, especially in leads I, II, and V4 (Table II).

The $P$ and $Q$ waves were normal and unchanged throughout. The P-R and QRS intervals tended to shorten in the febrile stage, but were never abnormal. The pulse rate increased by 6 beats/minute/degree Fahrenheit.

\section{Discussion}

Examination of E.C.G.s taken in the acute stage of leptospirosis, and comparison of them with others taken during recovery, showed that $90 \%$ of first records were abnormal. The chief abnormalities were a tachycardia, small QRS complexes, an increase in the size of the $S$ wave in leads I and V7, and flat or inverted $T$ waves (Fig. 1). The age and nationality of the patient, the duration of the illness, and the height of the fever did not influence these changes, which disappeared during the first 10 days, leaving only a slight S-T elevation in leads I and $\mathrm{V} 7$ on some records taken during convalescence.

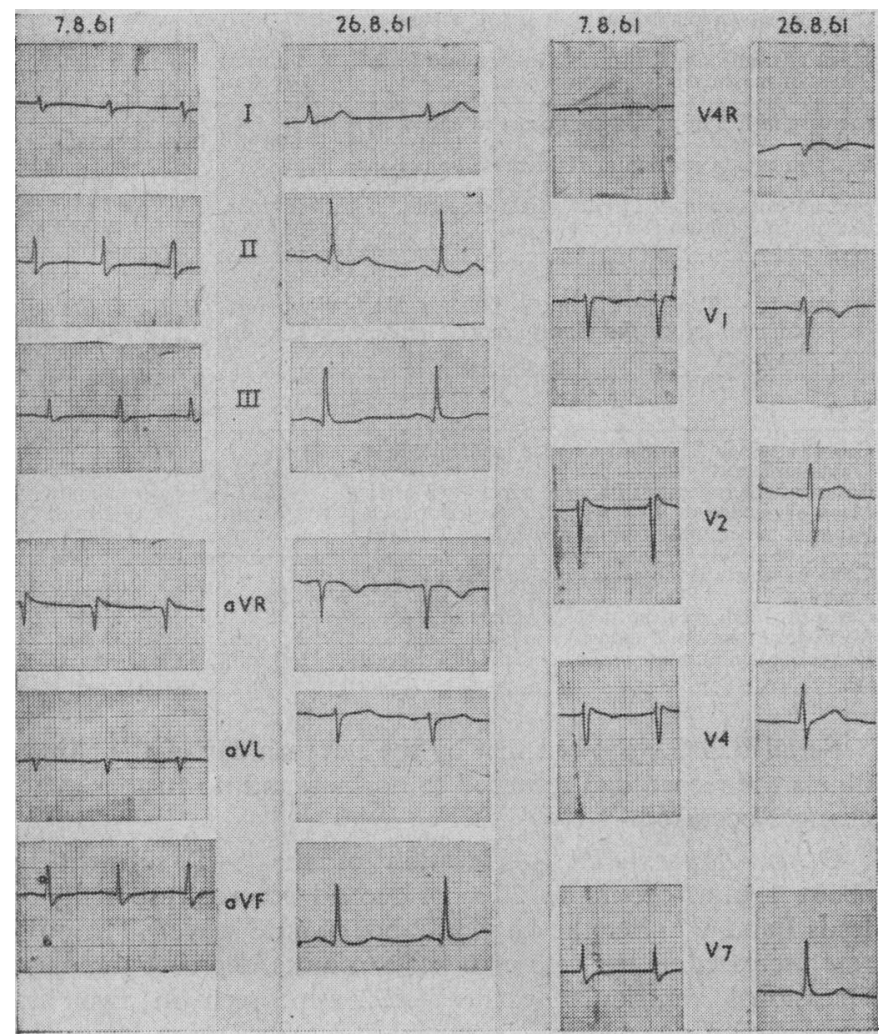

FIG. 1.-Serial records from a patient with leptospirosis.
Similar changes have been described or depicted before. Plate I in the article by Mackay-Dick and Robinson (1957) shows an increase in the height of $R_{I}$, the disappearance of $S_{I}$, a slight $S-T$ elevation, and a marked increase in the height of the $\mathrm{T}$ waves. The relative slowness of the pulse in proportion to the fever (a rise of 6 instead of the usual 7 to 10 beats/minute/ degree Fahrenheit) was noted by Dawson and Hume (1916-17). On the other hand, no evidence of a consistent change in the $\mathrm{P}-\mathrm{R}$ and $\mathrm{Q}-\mathrm{T}$ intervals was found, and, for obvious reasons, there was no evidence of the arrhythmias or pericarditis, descriptions of which have hitherto dominated the literature. The results confirm the predictions of Hume and Szekely (1944) and of Sodeman and Killough (1951) that cardiographic evidence of cardiac involvement may be found in the absence of physical signs, especially if serial records are examined.

Although the changes described occur regularly in leptospirosis, they are not peculiar to this disease. Examination of serial E.C.G. records from 18 otherwise healthy soldiers with malaria contracted under similar operational conditions revealed changes almost identical in nature, frequency, and degree. Seventy-eight per cent. of first records were outside the strict limits of normality, and nearly all altered during the recovery process (Tables I and II ; Fig. 2).

Among the common factors possibly responsible for the identical E.C.G. changes found in the two illnesses, fever is the most obvious. It is therefore interesting that similar changes have been reported in patients rendered febrile artificially by means of a hot-air cabinet. These included diminution in the height of the $\mathrm{R}$ waves, especially in lead II, an increase in the height of $S_{I}$, and depression of $T_{I}$ and $T_{I I}$, with slight elevation of the $S-T$ segment in leads II and III during recovery (Knies, 1941). Such changes have been attributed to acute diffuse coronary insufficiency caused by tachycardia and sympathetic stimulation (Lepeschkin, 1951). In febrile infections the exudation of plasma or cellular infiltrates between the muscle fibres may further interfere with oxygen diffusion.

If it is accepted that identical changes occur in these two groups of patients, and that similar changes occur in artificially induced fever, it cannot be said that the abnormalities found on

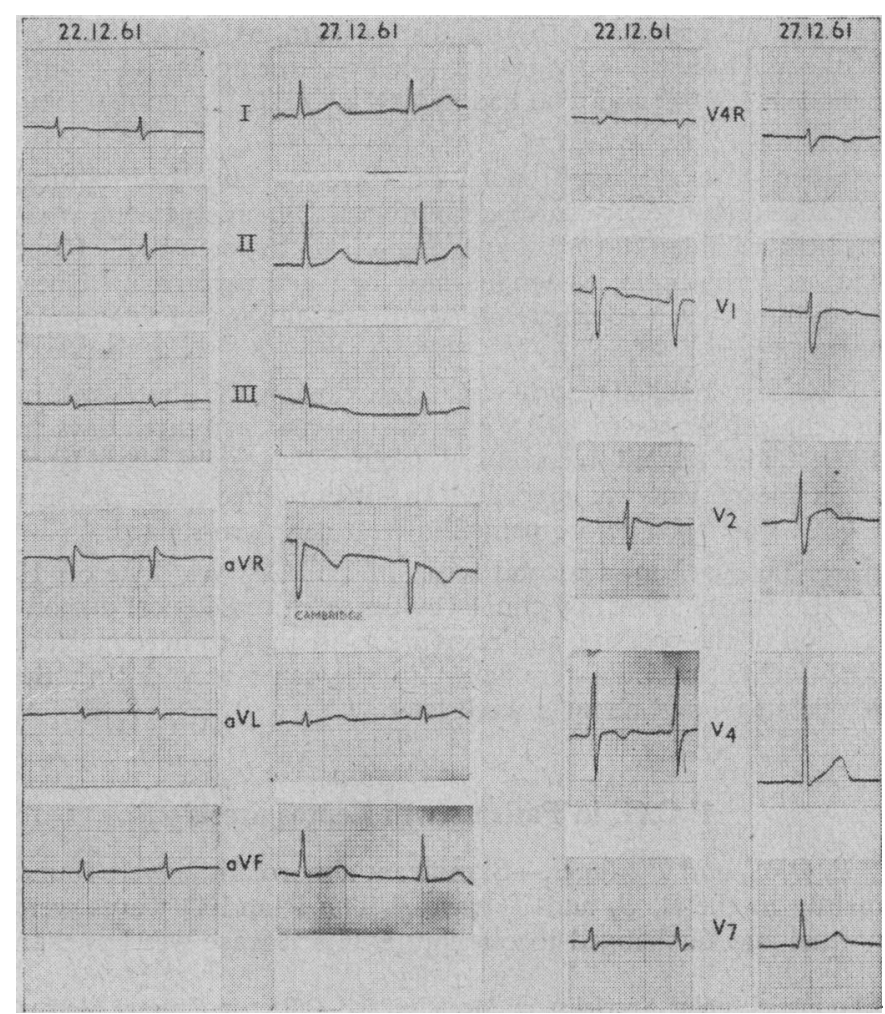

FIG. 2.-Serial records from a patient with malaria. 
routine cardiography in patients with uncomplicated leptospirosis are specifically due to that disease. Indeed, it seems probable that they are the non-specific result of a febrile infection. However, previous reports make it clear that pericarditis, endocarditis, and arrhythmias also occur in leptospirosis. These conditions are not seen in artificially induced fever, and cannot be accounted for in this way. Their pathogenesis is unknown, but they could be due to spontaneous bleeding in the myocardium or pericardium.

Spontaneous bleeding often occurs in leptospirosis. Nearly half the patients in this series bled from the lungs, the intestine, the skin, the nose, beneath the conjunctiva, or into the cerebrospinal fluid. A fifth had microscopic haematuria. This bleeding could be very severe indeed. Thus one patient who subsequently recovered from a gross generalized haemorrhagic tendency showed a fall of haemoglobin from $100 \%$ to $47 \%$ (packed cell volume 19\%) in seven days. A necropsy on a similar fatal case seen elsewhere in Malaya showed that the lungs, pleura, gastro-intestinal tract, retroperitoneal spaces, kidneys, heart, and pericardium were riddled with easily visible haemorrhages of varying sizes. Haemorrhage of this severity is uncommon, but milder internal bleeding must often occur. It is not necessary to surmise such an event to explain the E.C.G. changes observed in this series, but the occurrence of such a spontaneous bleed into the pericardium or into the mvocardium near the conducting tissue could, as suggested by Hume and Szekely (1944), account for the cardiac abnormalities not attributed to exudates, infiltrates, sympathetic overactivity, and fever.

\section{Summary}

Serial electrocardiographic studies were done on 25 patients with leptospirosis and 18 patients with malaria who had no evidence of cardiovascular disease on routine clinical examination.

Identical abnormalities were found in the majority of records in the two groups.

After comparison with findings reported in artificial hyperpyrexia, it is concluded that the abnormalities are the nonspecific result of a febrile infection.

A possible cause of arrhythmias and pericarditis in leptospirosis is discussed.

I wish to thank Dr. Paul Szekely for his help and advice with this study.

\section{REFERENCES}

Dawson, B., and Hume, W. E. (1916-17). Quart. F. Med., 10, 90.

Hume, W. E., and Szekely, P. (1944). Brit. Heart \%., 6, 135 .

Knies, P. T., (1941). Amer. Heart f., 22, 804.

Lepeschkin and Wilkins, Baltimore.

Mackay-Dick, J., and Robinson, J. F. (1957). f. roy. Army med. Cps, $103,186$.

Sodeman, W. A., and Killough, J. H. (1951). Amer. F. trop. Med., 31, 479.

\title{
Peripheral Sensorimotor Neuropathy Associated with a Localized Myeloma
}

\author{
D. I. RUSHTON,* M:B., CH.B.
}

Brit. med.7., 1965, 2, 203-205

Neurological manifestations in diseases of the reticuloendothelial system are not uncommon and are said to occur in $15-50 \%$ of cases (Aita, 1962). The vast majority of these cases show neurological symptoms as a result of direct invasion or compression of the nervous tissues. However, in a small number of cases neurological manifestations are severe and yet there is no direct involvement of the nervous system. These may be similar to those syndromes associated with carcinoma.

Victor at al. (1958) presented five cases of sensorimotor neuropathy associated with myeloma, in three of which post-mortem examination revealed no evidence of invasion of the nervous system. Barron et al. (1960) described three cases in which local infiltrations of the peripheral nerves by plasma cells led to demyelination of the adjacent nerve fibres. Other cases of neuropathy associated with myeloma have been reported by Hassan and Yousef (1959) and Boudin et al. (1961), and the condition has been noted by Osserman (1959).

The case reported below is believed to be a case of the type described by Victor et al. (1958).

\section{Case History}

A man aged 45 first noticed coldness and numbness of his feet in January 1962. This was dismissed as being due to the cold weather. However, the condition progressed and paraesthesiae of his lower limbs developed below the knees. In July he had marked difficulty in walking and experienced numbness of his hands.

In August he was admitted to the Midland Nerve Hospital for investigation. At this time he had great difficulty in walking, paraesthesiae of the hands and feet, and increasing clumsiness when using his hands.
Clinical examination revealed extensive neurological manifestations in an otherwise normal male. These were: The upper limbs showed loss of power, areflexia, impaired pinprick and vibration sense, and loss of touch sensation below the elbows. The lower limbs showed gross loss of power, areflexia, absent joint sense, and loss of pinprick and vibration sense below the costal margin. The plantar response was absent. These findings were symmetrical.

After admission his condition slowly progressed, and while in hospital he developed deep-vein thrombosis of his calf; this led to pulmonary embolus, from which he made a satisfactory recovery with the aid of anticoagulant therapy.

On 6 September a bony lesion of D 11 was first noted on an $x$-ray film ; it was thought to be myeloma, but no other confirmation of this diagnosis was obtained.

The neuropathy was provisionally diagnosed as a form of GuillainBarré syndrome, and steroid therapy was begun. This led to a slight temporary improvement in the power of his legs; but it was not maintained, and the symptoms and progression of the disease continued.

In May 1963 he was transferred to Selly Oak Hospital. At this time he had paraesthesiae of all limbs, intermittent dysarthria, areflexia, gross impairment of sensation, and severe attacks of pain in the lower limbs. Muscular weakness was severe. The fundi showed blurring of the disks. On exercise he became very dyspnoeic, probably as a result of involvement of his respiratory muscles. Gradually over the next few months his condition deteriorated and he developed gangrene of the right fifth toe. By August severe sensorimotor neuropathy of his upper limbs, shoulders, and lower limbs was evident. The extremities were cyanosed and the gangrene of the right foot was progressing.

* Department of Pathology, Selly Oak Hospital, Birmingham. Now Research Fellow, Department of Morbid Anatomy, Children's Hospital, Birmingham. 